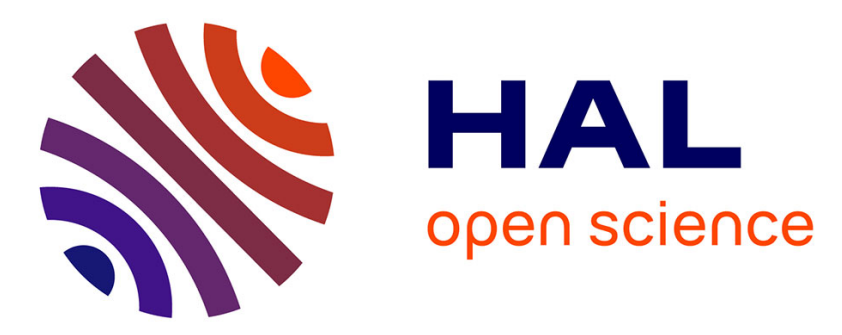

\title{
Kinetic characteristics of the thermal hysteresis in an incommensurate system
}

\author{
G. Errandonéa, J.C. Tolédano, A. Litzler, H. Savary, J. Schneck, J. Aubrée
}

\section{To cite this version:}

G. Errandonéa, J.C. Tolédano, A. Litzler, H. Savary, J. Schneck, et al.. Kinetic characteristics of the thermal hysteresis in an incommensurate system. Journal de Physique Lettres, 1984, 45 (7), pp.329-334. 10.1051/jphyslet:01984004507032900 . jpa-00232351

\section{HAL Id: jpa-00232351 https://hal.science/jpa-00232351}

Submitted on 1 Jan 1984

HAL is a multi-disciplinary open access archive for the deposit and dissemination of scientific research documents, whether they are published or not. The documents may come from teaching and research institutions in France or abroad, or from public or private research centers.
L'archive ouverte pluridisciplinaire HAL, est destinée au dépôt et à la diffusion de documents scientifiques de niveau recherche, publiés ou non, émanant des établissements d'enseignement et de recherche français ou étrangers, des laboratoires publics ou privés. 
Classification

Physics Abstracts

$64.70 \mathrm{~K}-68.30 \mathrm{~J}$

\title{
Kinetic characteristics of the thermal hysteresis in an incommensurate system
}

\author{
G. Errandonéa, J. C. Tolédano, A. Litzler, H. Savary, J. Schneck and J. Aubrée \\ C.N.E.T., 196, rue de Paris, 92220 Bagneux, France \\ (Reçu le 22 décembre 1983, révisé le 7 février 1984, accepté le 14 février 1984)
}

\begin{abstract}
Résumé. - Nous avons examiné l'hystérésis thermique qui se produit dans la phase incommensurable du niobate de baryum et de sodium. La cinétique de ce phénomène est déterminée pour la première fois. Nous observons des effets de relaxation associés à des temps caractéristiques de plusieurs heures. Ces effets provoquent de larges variations dans la forme des cycles de chauffage/refroidissement qui sont interprétées sur la base d'une interaction entre la modulation incommensurable et des défauts mobiles. Des effets semblables devraient être observés dans d'autres systèmes réels possédant des phases incommensurables.
\end{abstract}

\begin{abstract}
The anomalous thermal hysteresis occurring in an incommensurate phase has been investigated in barium sodium niobate. The kinetics of this phenomenon is determined for the first time. We observe relaxation effects with characteristic times of several hours. They are associated with large variations of the heating/cooling plots which are interpretated by assuming that the incommensurate modulation interacts with mobile defects. Similar effects should occur in other real systems with incommensurate phases.
\end{abstract}

An anomalous thermal hysteresis has been detected in a number of incommensurate phases, both in insulating materials and in low-dimensional conductors [1-4]. This hysteresis is of a different nature than that usually associated with a first-order transition. It occurs each time the temperature trend is reversed within the range of the incommensurate phase.

In this letter, we examine, for the first time, kinetic effects associated with the presence of an incommensurate phase, by means of an experimental study of barium sodium niobate (BSN). We show that the observed characteristics of the thermal hysteresis have a time dependence, and that slow relaxation processes, related to the existence of the incommensurate phase, take place, in the system.

BSN is known [4] to possess a displacive incommensurate modulation between $T_{\mathrm{L}} \approx 270{ }^{\circ} \mathrm{C}$, and $T_{1} \approx 300^{\circ} \mathrm{C}$, with a single direction of the modulation vector $\mathbf{k}$. A peculiarity of this material is that $T_{\mathrm{L}}$ corresponds to an incomplete "Lock-in " : below $T_{\mathrm{L}}$, a small incommensurability persists $\left(\left|k-k_{0}\right| / k_{0} \approx 1 \%\right.$ ), in the so-called quasi commensurate phase (QCP) [4]. The normal crystalline phase, stable above $T_{\mathrm{l}}$, is tetragonal while both the incommensurate phase (INCP) and the QCP are orthorhombic. Thus, in the two latter phases, there is a spontaneous birefringence $\left(n_{\mathrm{a}}-n_{\mathrm{b}}\right)$ induced by the point symmetry breaking at $T_{\mathrm{I}}$. In the temperature dependence of $\left(n_{\mathrm{a}}-n_{\mathrm{b}}\right), T_{\mathrm{L}}$ is indicated by a convexity change (the inflexion on Figs. $1 \mathrm{~b}$ and 2 ) while $T_{\mathrm{I}}$ corresponds to the vanishing point of this quantity. Our investigation of the thermal hysteresis was 

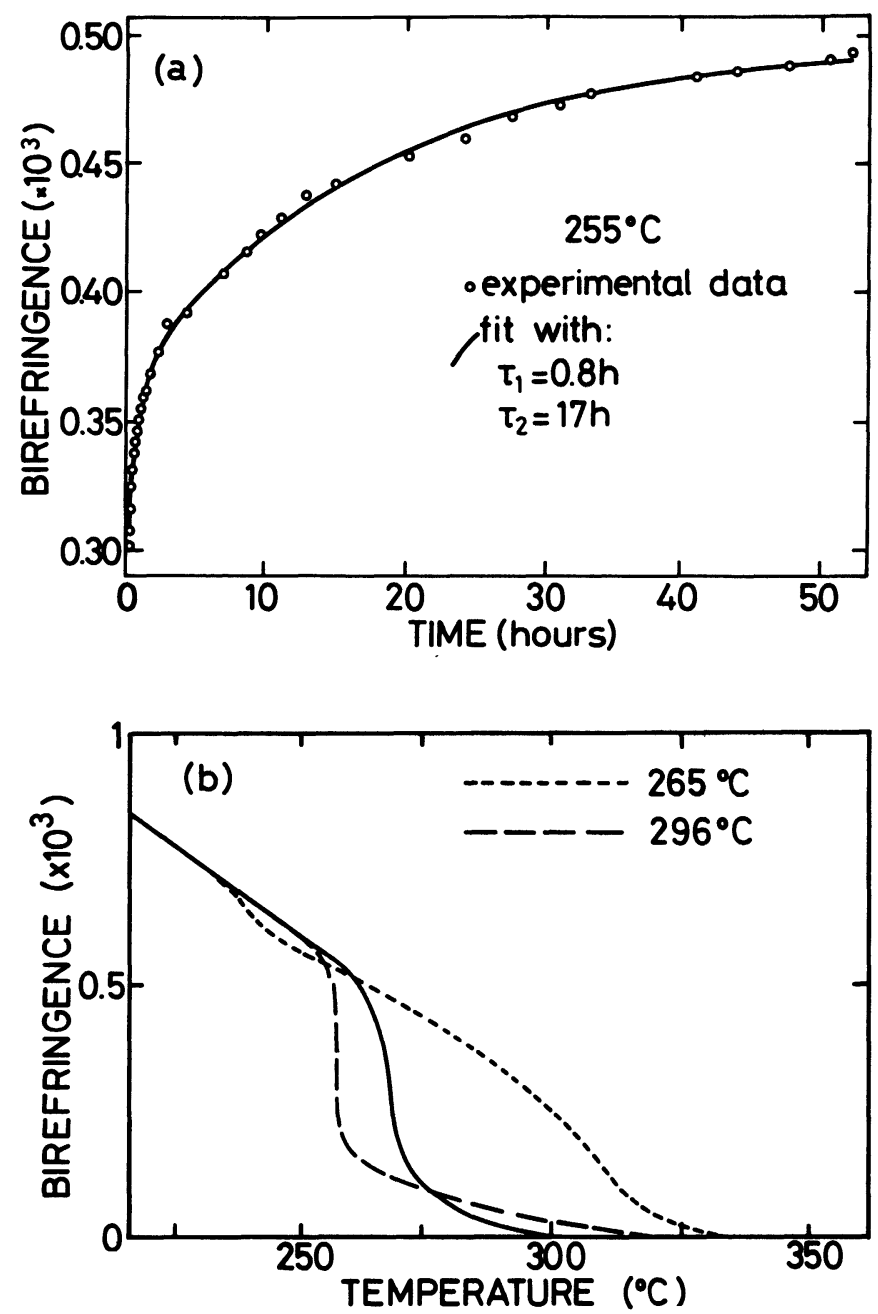

Fig. 1. - a) Relaxation of the spontaneous birefringence of BSN at $T_{\mathrm{A}}=255^{\circ} \mathrm{C}$. b) Heating runs following the " annealing " at two temperatures $T_{A}$ located respectively above and below the inflexion point (lockin) of a reference heating plot (solid line) obtained after cycling repeatedly the sample at $2.5^{\circ} \mathrm{C} / \mathrm{min}$.

mainly achieved by means of the measurement of the optical birefringence $\left(n_{\mathrm{a}}-n_{\mathrm{b}}\right)$ as a function of time and temperature in the $20^{\circ} \mathrm{C}-350^{\circ} \mathrm{C}$ range. Above $T_{\mathrm{l}}$, as $\left(n_{\mathrm{a}}-n_{\mathrm{b}}\right)=0$, we also performed additional measurements of the $\varepsilon_{a}$ component of the dielectric permittivity at $1000 \mathrm{~Hz}$.

The composition of all real samples of BSN is known [5] to depart from the stoichiometric formula $\mathrm{Ba}_{2} \mathrm{NaNb}_{5} \mathrm{O}_{15}$. It has been pointed out [5] that the main structural defect introduced by the non-stoichiometry was likely to be the occurrence of vacancies at the sodium sites. Though all samples display similar qualitative features as those described below, the specific results presented in this letter are relative to a sample with the formula $\mathrm{Ba}_{2.11} \mathrm{Na}_{0.84} \mathrm{Nb}_{4.99} \mathrm{O}_{15}$, as determined by radiochemical and electron microprobe analyses [5].

In order to analyse the thermal hysteresis, various types of measuring procedures were applied to the sample. 


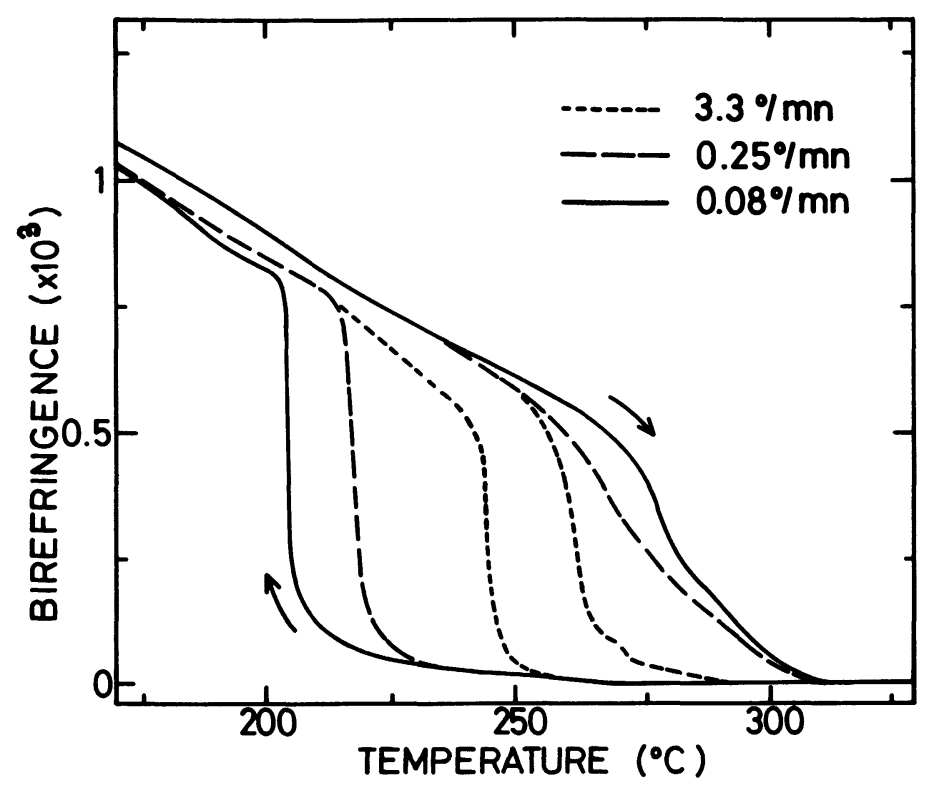

Fig. 2. - Birefringence « limit plots » relative to different heating/cooling rates. Each plot is obtained by repeatedly cycling the sample at a fixed rate indicated on the figure. The thermal hysteresis decreases for increasing rates.

First, we have interrupted a heating or a cooling run at different temperatures $T_{\mathrm{A}}$ and, while maintaining the sample at this temperature, measured the time dependence of $\left(n_{\mathrm{a}}-n_{\mathrm{b}}\right)$ or of $\varepsilon_{\mathrm{a}}$. In this experiment, we observe a slow evolution of the measured quantity which approaches, at progressively decreasing rates, a limit value reached after a time which is typically two to four days (Fig. 1a). This relaxation inexistant below $200^{\circ} \mathrm{C}$, has a large amplitude between $250^{\circ} \mathrm{C}$ and $300^{\circ} \mathrm{C}:$ an 8 -fold increase of the value of $\left(n_{\mathrm{a}}-n_{\mathrm{b}}\right)$ is noted for instance at $280{ }^{\circ} \mathrm{C}$. The fitting of its time dependence by exponential laws requires two relaxation times, one in the range 0.5-3 hours, and the other in the range 10-50 hours. We can note however that other simple decay laws, suggested by the case of spin-glasses [6] (logarithmic or power laws) also provide a good fit.

A relaxation having the same characteristics is revealed in the normal phase by the measurement of $\varepsilon_{\mathrm{a}}$. This relaxation is observed only after heating the sample across the INCP. Moreover, if after the end of a relaxation in the normal phase the sample is brought to another temperature within this phase no further relaxation is detected.

The persistence of relaxations in the normal phase can be considered as a strong indication that defects are involved in the underlying processes, since this phase is expected to display the behaviour of an ordinary crystal. Indeed, in a crystal, the occurrence of such slow relaxation times is only encountered in the evolution of some defect pattern, such as the diffusion of point defects through the structure. The additional feature, in BSN, that a crossing of the INCP is a prior condition for the observation of relaxations in the normal phase indicates that the conjectured defects interact with the modulation. The interaction of fixed defects with an incommensurate modulation corresponds to the situation usually considered theoretically [7]. In that case, it is found that the modulation tends to be pinned by the defects, and that it distorts in order to adapt to the pattern of the defects. Here, we assume that the converse effect takes place, and that we have to deal with mobile point defects (e.g. the mentioned sodium vacancies of BSN) which are induced to diffuse through the structure by their interaction with the incommensurate modulation : the 
observed relaxations are interpretated as related to the migration of the defects tending to establish a periodic spatial distribution of defects in order to adapt to the periodicity of the modulation, both in the INCP and in the QCP.

In this picture, the relaxations detected in the normal phase will reflect the restoration of a uniform distribution of the defects through a thermally activated diffusion (since no modulation is present in this phase). When completed, a uniform pattern of defects should not give rise to any further relaxation as long as one stays in the normal phase. This inference is clearly in agreement with the above stated experimental observation.

Let us analyse the consistency of the preceding mechanism with the other anomalous effects disclosed by our measurements.

Figure $1 \mathrm{~b}$ illustrates the results of a second series of experiments. In this case, the end of the relaxation at a temperature $T_{\mathrm{A}}$ (which we can consider as an " annealing " of the defects in the force field produced by the modulation) is followed by a rapid cooling down to room temperature, and then by a heating run at a constant, fixed rate $\left(2.5^{\circ} \mathrm{C} / \mathrm{min}\right)$ during which $\left(n_{\mathrm{a}}-n_{\mathrm{b}}\right)$ is measured. The results show that depending if $T_{\mathrm{A}}$ is either slightly above or slightly below the inflexion point of the birefringence plot initially considered (Fig. 1b) the subsequent heating runs are separated by over $50^{\circ} \mathrm{C}$ in the region of $T_{\mathrm{L}}$. The shapes of the plots also differ in a major way, showing either a sharp discontinuity at $T_{\mathrm{L}}$, or a smooth vanishing of $\left(n_{\mathrm{a}}-n_{\mathrm{b}}\right)$. These effects resemble, in a considerably enhanced way to the " memory effect " recently described in thiourea [3] : the heating run bears a memory of the annealing temperature $T_{\mathrm{A}}$ preceding it.

As already recognized by Jamet et al. [3], an interpretation of this memory effect can be given in terms of mobile defects interacting with the modulation : the annealing at $T_{\mathrm{A}}$ sets in the sample a spatial distribution of defects patterned according to the state of the modulation at $T_{\mathrm{A}}$. This pattern is almost frozen during the rapid cooling, and the subsequent run reveals the defect distribution through its influence on the temperature dependence of the birefringence. Consistently with this picture, figure $1 \mathrm{~b}$ shows that the annealings in the INCP or in the QCP have respectively the effects of inducing the anticipated onset $\left(T_{\mathrm{L}} \approx 260^{\circ} \mathrm{C}\right)$, or the retarded onset $\left(T_{\mathrm{L}} \approx 310^{\circ} \mathrm{C}\right)$ of the INCP in the subsequent heating run. The assumption that the memory effect is not an intrinsic property of the incommensurate phase, and that it also involves defects, is further supported by the observation that it is not erased by a brief crossing of the normal phase.

A third type of experiments has consisted in thermally cycling the sample between $20^{\circ} \mathrm{C}$ and $300^{\circ} \mathrm{C}$ at a constant rate comprised between $0.08{ }^{\circ} \mathrm{C} / \mathrm{min}$ and $4{ }^{\circ} \mathrm{C} / \mathrm{min}$. For each rate, we obtain, after a few cycles, an accurately reproducible plot of $\left(n_{\mathrm{a}}-n_{\mathrm{b}}\right)$ which does not depend on the previous thermal history of the sample. By contrast there is a very large dependence of this « limit plot " on the heating/cooling rate (Fig. 2). For increasing rates, there is, in particular, a considerable decrease of the magnitude of the thermal hysteresis in the region of $T_{\mathrm{L}}$, from $80^{\circ} \mathrm{C}$ down to $15^{\circ} \mathrm{C}$.

This striking influence of the speed of the runs can be satisfactorily understood on the basis of the stated assumptions. We consider here two aspects of the experimental results.

As seen on figure 2, the cooling portion of the runs discloses a downward shift of the range of the INCP on cooling, for decreasing speeds. This effect is accounted for by noting that during the crossing of the normal phase preceding the cooling run, the mobile defects have more time to approach a uniform spatial distribution as the speed is decreased. As a consequence this distribution will oppose more efficiently the onset, on cooling, of the incommensurate phase and provoke a downward shift of its temperature range. This has been checked by increasing the speed of a run in the sole temperature range of the normal phase, and consistently observing a smaller downward shift of the INCP.

On the other hand, the fast heating runs (e.g. $3.3^{\circ} \mathrm{C} / \mathrm{min}$ ) display an anticipated onset of the INCP at $T_{\mathrm{L}} \approx 265^{\circ} \mathrm{C}$ (Fig. 2), very similar to the one obtained after an " annealing " of the sample in the INCP (Fig. 1b), in spite of the fact that the crossing time of this phase $(<10 \mathrm{~min})$ is 
much shorter than the relaxation times involved in the annealing. Such a result seems to indicate that, although the sample crosses during a longer time the QCP than the INCP, it keeps the memory of the latter phase. The modulation seems to less efficiently drive the diffusion of the defects in the QCP than in the INCP, and this is, in spite of the fact that the amplitude of the modulation is larger in the QCP than in the INCP.

We can understand this feature by noting that a modulation with a large period (as in the QCP) is likely to exert a smaller effective force on the defects than a modulation with a shorter period (as in the INCP). Indeed, if the period is large, the phase of the modulation varies slowly over the distance separating the neighbouring structural sites which are successively occupied by a defect during its diffusion. As a consequence, the displacement of a defect between consecutive sites will not significantly modify its situation with respect to the modulation, and accordingly will not significantly decrease the interaction energy.

In conclusion, we have shown that the various effects observed are consistent with the occurrence of an interaction between the incommensurate modulation and mobile defects. This interpretation is more specifically supported by the observations relative to the normal phase following a crossing of the INCP. The experimental procedures used have induced large variations in the thermal hysteresis and have therefore established that, in BSN, this phenomenon is in great part related to the considered interaction. The nature of the mobile defects in BSN is not yet elucidated. However preliminary studies [5] show that the sodium vacancies present in the samples have a suitable concentration and the possibility of migrating easily along the modulation direction. This suggests that they can be considered to be the relevant mobile defects.

The kinetic effects described here are likely to be general features of real systems with incommensurate phases. The memory effect was actually recognized by Jamet et al. [3] in thiourea, and also in $\mathrm{Rb}_{2} \mathrm{ZnCl}_{4}$ by Unruh [2]. Since we have shown that the kinetics of the thermal hysteresis seems to have the same microscopic origin, this kinetics should also be detected in these substances, though perhaps with a smaller amplitude. Indeed, a slow relaxation of the nuclear magnetic resonance lineshape has been pointed out by Pezeril et al. [2] in $\mathrm{Rb}_{2} \mathrm{ZnCl}_{4}$. More generally, the large influence of the conditions of the measurements and of the thermal history of the sample on the properties of incommensurate substances has been noted by a number of authors [1-4], and is likely to be related to the type of phenomena described here.

Note added in proof. - During the submission of this manuscript a paper has been published by Mihaly et al. [8] showing the occurrence of similar relaxations in $\mathrm{TaS}_{3}$. It is striking to note that they find characteristic times of the same magnitude as in BSN (decays which last several hours). These results confirm the generality of the described effects (though the interpretation of Mihaly et al., of a more restricted set of experimental data, does not consider the possibility of mobile defects).

\section{References}

[1] Ellenson, W. D., Shapiro, S. M., Shirane, G. and Garito, A. F., Phys. Rev. B 16 (1977) 3244 ; Fleming, R. M., Moncton, D. E., McWhan, D. B. and Di Salvo, F. J., Phys. Rev. Lett. 45 (1981) 576 ; Strukov, B. A., Arutyunova, V. M. and Uesu, Y., Sov. Phys., Solid State 24 (1982) 1732.

[2] Mashiyama, H., Tanizaki, S. and Hamano, K., J. Phys. Soc. Jpn 51 (1982) 2538 and references therein ; UnRuh, H. G., J. Phys. C 16 (1983) 3245 ;

Pezeril, M. and Fayet, J. C., J. Physiquie Lett. 43 (1982) L-267.

[3] JAMet, J. P. and Lederer, P., J. Physique Lett. 44 (1983) L-257.

[4] SCHNeCK, J. and Denoyer, F., Phys. Rev. B 23 (1981) 383 ;

Schneck, J., Tolédano, J. C., Joffrin, C., Aubrée, J., Joukoff, B. and Gabelotaud, A., Phys. Rev. B 25 (1982) 1766 ;

Tolédano, J. C. and SchneCK, J., Solid State Commun. 16 (1975) 1101. 
[5] SCHNECK, J., Thesis (University of Paris VI, 1982) Unpublished.

[6] GuY, C. N., J. Phys. F 8 (1978) 1309.

[7] Fukuyama, H. and Lee, P. A., Phys. Rev. B 17 (1978) 535.

McMillan, W. L., Phys. Rev. B 12 (1975) 1187;

NaKanishi, K., J. Phys. Soc. Jpn 46 (1979) 1434.

[8] Mihaly, G. and Mihaly, L., Phys. Rev. Lett. 52 (1984) 149. 